\title{
Effects of cobalt deficiency in pregnant and post-parturient ewes and their lambs
}

\author{
BY W. R. H. DUNCAN, E. RONA MORRISON AND G. A. GARTON \\ Rowett Research Institute, Bucksburn, Aberdeen AB2 9SB
}

(Received 10 November 1980 - Accepted 30 April 1981)

\begin{abstract}
1. Two groups of ewes were fed on a cobalt-deficient diet throughout pregnancy; one group (group A) was given the diet from the beginuing of pregnancy, whilst the other (group B) received the diet for 16 weeks before mating. The ewes in group A continued to receive the diet for 12 weeks post-partum.

2. The vitamin $B_{12}$ content of serum was estimated on three occasions before parturition and, for group $A$ ewes, at 12 weeks post partum. Urinary concentration of methylmalonic acid was also determined at intervals before the lambs were born.

3. Serum values for vitamin $B_{12}$ indicated that the ewes in both groups were depleted of the vitamin, though those in group B were more severely affected, as was evidenced by the high incidence of perinatal mortality among the lambs born to these ewe:s. Perinatal mortality appeared to be associated with abnormally-high values for urinary concentration of methylmalonic acid.

4. Analysis of liver lipids and adipose tissue triacylglycerols of some of the vitamin $B_{12}$-deprived lambs which died before, or within $1 \mathrm{~d}$ of, birth showed that, compared with the corresponding tissues of control lambs, these lipids contained unusually high proportions of odd-numbered fatty acids (mostly 15:0, 17:0 and 19:0). This observation is discussed in relation to the likelihood that, in vitmain $\mathbf{B}_{12}$-deprived lambs, propionate becomes available as a primer unit for fatty acid synthesis when the metabolism of its carboxylation product, methylmalonic acid, is impaired due to partial lack of a vitamin $\mathbf{B}_{12}$-containing enzyme system.
\end{abstract}

For their supply of vitamin $B_{12}$ herbivorous animals are dependent on its production by bacteria which inhabit the alimentary tract and which utilize cobalt from the host's diet for this purpose. In some species, such as the rabbit, coprophagy is essential for the animal to obtain the vitamin $B_{12}$ which results from synthesis in the lower gut, whilst ruminants rely on synthesis of the vitamin by rumen bacteria.

Many of the early observations on the Co requirements of sheep and on the metabolic consequences of Co defiriency have been reviewed and summarized by Underwood (1977). Suffice it to mention here that the characteristic features of Co deficiency in sheep, namely inappetance and associated weight loss and anaemia, usually become apparent when the serum content of the vitamin falls to approximately $200 \mathrm{pg} / \mathrm{ml}$. Because vitamin $B_{12}$ is an essential component of at least two enzyme systems in the body, namely, methylmalonylCoA mutase (EC 5.4.9.92) and a methyltransferase involved in methionine biosynthesis, the metabolic consequerices of reduced availability of the vitamin to the sheep include enhanced urinary outpul: of methylmalonic acid (MMA) and of formiminoglutamic acid (Gawthorne, 1968). Because ruminants are particularly dependent on gluconeogenesis from propionate, the urinary loss of its primary metabolite, MMA, could have serious physiological consequences.

Under grazing conditions, lambs are particularly sensitive to Co deficiency, followed by mature sheep, calves and adult cattle, in that order (Andrews, 1956). In an experiment in which ewes grazing Co-deficient pasture were treated intraruminally with cobaltic oxide pellets, Andrews \& Stephenson (1966) found, rather surprisingly, that lambs born to these ewes developed signs of Co deficiency when they were between 11 and 17 weeks old (i.e. before weaning) and tha: some of them died. It is therefore perhaps remarkable that, as far as we are aware, no studies have hitherto been reported on the physiological and metabolic consequences of the experimental induction of Co deficiency in pregnant ewes and their lambs. 
EX PER I MEN T A L

Animals and their diet

Fifteen 1-year-old Blackface ewes, purchased from an upland farm in Angus, were housed indoors and fed on dried grass for 2 months until they were mated. The animals were then put into individual, adjacent, wooden pens and each was given daily access to $1.5 \mathrm{~kg}$ of a diet which consisted of $(\mathrm{g} / \mathrm{kg})$ : hay 700 , maize meal 261 , sodium chloride 15 , dicalcium phosphate 15 , urea 8 , mineral and vitamin mixture 1 ; this mixture comprised $(\mathrm{mg} / \mathrm{kg}$ diet): magnesium oxide $200, \mathrm{ZnSO}_{4} .7 \mathrm{H}_{2} \mathrm{O} 150, \mathrm{MnSO}_{4} .4 \mathrm{H}_{2} \mathrm{O}, 80$, potassium iodate 1 , DL$\alpha$-tocopherol 20 , retinyl palmitate $1 \cdot 5$, vitamin D 0.025 . Water was freely available. The hay had a low content of Co $(0.05 \mathrm{mg} / \mathrm{kg})$, as had the maize meal $(<0.03 \mathrm{mg} / \mathrm{kg})$ and thus the diet as a whole was not expected to meet the animals' requirement for Co, a minimal value for which is generally taken to be $0.08 \mathrm{mg} / \mathrm{kg}$ diet (Underwood, 1977). Three of the ewes were designated as control animals and each received supplementary Co (as cobalt sulphate) in its drinking water (70 $\mu \mathrm{g} / \mathrm{l})$. After 12 weeks only nine ewes were found to be pregnant and they are subsequently referred to as group $A$ which comprised seven experimental animals (nos. A1-A7) and two control ewes (nos. A8 and A9). After 4 weeks the remaining six ewes were mated again and all became pregnant; these ewes consisted of five experimental animals (nos. B1-B5) and one control animal (no. B6). These sheep constituted group $B$ which was augmented by the inclusion of a further two control pregnant Blackface ewes (nos. B7 and B8).

A few days before term the ewes in each group were transferred to bigger pens provided with straw. Following the birth of their lambs, each ewe in group A, whether or not it was suckling its progeny, was offered the low-Co diet and water (with or without added Co) for a period of 12 weeks; the lambs had access to the same food as their dams until they died, or were killed, or were weaned. After this 12-week period the experiment was terminated, though the two lambs which remained with their Co-depleted dams until weaning at 12 weeks of age were fed on the Co-deficient regimen for a further 4 and 20 weeks respectively.

The lambs born to the ewes in group B were stillborn, died at birth or were killed within $1 \mathrm{~d}$ of birth and so the ewes were not subjected to further experimental investigation.

\section{Monitoring of vitamin $B_{12}$ depletion}

The food intake of each ewe was determined daily and the animals were weighed fortnightly. On three occasions, at 2-3 weekly intervals pre partum, each ewe was put into a 'metabolism cage' to allow collection of a $24 \mathrm{~h}$ sample of urine which was analysed for its content of MMA essentially according to Giorgio \& Plaut (1965). In preliminary trials the method was unreliable until it became apparent that, to obtain complete development of the (green) diazo colour, it was necessary to ensure complete exclusion of carbon dioxide by purging the reaction mixture with a continuous stream of nitrogen bubbles.

At the same times that urine was obtained blood samples were also taken and allowed to clot; the vitamin $B_{12}$ content of the serum was determined by the radio-dilution procedure using analysis kits supplied by The Radiochemical Centre, Amersham, Bucks. Blood samples for vitamin $B_{12}$ analysis were also taken 12 weeks post partum from the ewes in group $\mathbf{A}$ and from most of their lambs at the time of death.

\section{Lipid analyses}

The livers and samples of adipose tissue were removed for subsequent lipid analysis from five of the vitamin $B_{12}$-deprived lambs which were stillborn or died at birth or were killed within $1 \mathrm{~d}$ of birth; similar tissue samples were obtained from three control lambs which 
Table 1. Effect of cobalt deficiency in pregnant ewes (group $A$ ) on serum vitamin $B_{12}$ values and urinary output of methylmalonic acid (MMA)

\begin{tabular}{crrrrrrr}
\hline \hline & \multicolumn{3}{c}{ Serum vitamin $B_{12}(\mathrm{pg} / \mathrm{ml})$} & & \multicolumn{3}{c}{ Urinary MMA $(\mu \mathrm{g} / \mathrm{ml})$} \\
\cline { 3 - 4 } \cline { 5 - 7 } $\begin{array}{c}\text { No. of weeks pre partum... } \\
\text { Ewe no. }\end{array}$ & 5 & 3 & 1 & & 5 & 3 & 1 \\
\hline A1 & 150 & 155 & 165 & & 52 & 57 & 76 \\
A2 & 270 & 210 & 245 & & 50 & 103 & 102 \\
A3 & 330 & 275 & 395 & & nd & nd & nd \\
A4 & 220 & 190 & 255 & & 90 & 95 & nd \\
A5 & 240 & 235 & 280 & & 68 & 30 & 21 \\
A6 & 340 & 175 & 300 & & 102 & 93 & nd \\
A7 & 300 & 155 & 205 & & 209 & 263 & 296 \\
A8* & 1380 & $>2000$ & 1300 & & 29 & 41 & 54 \\
A9* & 1680 & $>2000$ & $>2000$ & & 40 & 42 & 55 \\
\hline \hline
\end{tabular}

nd, not determined.

- Control animal given supplementary cobalt.

were killed soon after birth. Total lipids, which were extracted from liver with a mixture of chloroform and me:hanol (Christie, 1973), were separated into neutral lipids and phospholipids by chromatography on silicic acid columns (Feliński et al. 1964). Triacylglycerols were extracted from adipose tissue with acetone (Garton et al. 1972). The liver neutral lipids and the aclipose tissue triacylglycerols were saponified with $0.5 \mathrm{M}$-potassium hydroxide in ethanol and the recovered fatty acids were converted to methyl esters by refluxing with excess methanol containing sulphuric acid $(1: 100, \mathrm{w} / \mathrm{w})$. Liver phospholipids were subjected to direct methanolysis (Christie, 1973) to obtain their component fatty acids in the form of methyl esters.

Fatty acid methyl esters were analysed for their content of odd-numbered fatty acids (ONFA) and branched-chain fatty acids (BCFA) by gas-liquid chromatography as described previously by Garton et al. (1972).

\section{RESULTS}

\section{Group $A$ ewes and their lambs}

During pregnancy the eives in this group consumed the full amount of food $(1.5 \mathrm{~kg})$ which was offered daily and they gained weight steadily. All lambed at normal term (21 weeks); twins were born to three of the experimental ewes (nos. A4, A5 and A7 in Table 1), though one pair of twins (that biorn to ewe A7) died at birth. Except for the latter lambs which were underweight $(1.5$ and $1 . \% \mathrm{~kg})$, the weights of all the others at birth were normal, i.e. between 3.0 and $5.0 \mathrm{~kg}$.

The values for serum vitamin $B_{12}$ and urinary MMA of the ewes at 1,3 and 5 weeks pre partum are given in Talsle 1. It is evident that the ewes which were not given $\mathrm{Co}_{0}$ in their drinking water were depleted of vitamin $B_{12}$ and that the serum values were low when the first blood samples were taken 5 weeks before lambing. Nevertheless, as already noted, the animals maintained their appetites and, with one notable exception, did not excrete amounts of MMA which could be considered unusually high. The exception (ewe A7) was the animal which produced the underweight twins which died at birth.

From the time the lambs were born all the vitamin $B_{12}$-depleted ewes began to lose their appetites and their serurn levels of the vitamin declined to very low values $(100-200 \mathrm{pg} / \mathrm{ml})$ within 4 weeks post partum and, 8 weeks later, to the values given in Table 2. Nevertheless, 
Table 2. Effect of cobalt deficiency in ewes (group A) on serum vitamin $B_{12}$ values 12 weeks after parturition

\begin{tabular}{ccccc}
\hline \hline & Ewe no. & $\begin{array}{c}\text { Serum vitamin } \\
\mathbf{B}_{12}(\mathrm{pg} / \mathrm{ml})\end{array}$ & $\begin{array}{c}\text { No. of } \\
\text { lambs suckled }\end{array}$ & $\begin{array}{c}\text { Period lambs were } \\
\text { suckled (weeks) }\end{array}$ \\
\hline A1 & 100 & 1 & 12 \\
A2 & 110 & 1 & 12 \\
A3 & 140 & 1 & 1 \\
A4 & 60 & 2 & 10 \\
A5 & 35 & 2 & 10 \\
A6 & 105 & 1 & 5 \\
A7 & 85 & $0 \dagger$ & 12 \\
A8* & $>2000$ & 1 & 12 \\
\hline A9* $^{*}$ & 1400 & 1 & \\
\hline
\end{tabular}

- Control animal given supplementary cobalt.

+ Twin lambs died at birth.

they suckled their lambs, albeit inadequately, as judged by the general unthriftiness and poor weight gains of the lambs compared with those born to the control ewes. One lamb (that born to ewe A3) was septicaemic when it died $7 \mathrm{~d}$ after birth and another lamb (born to ewe A6) died following castration at 5 weeks of age.

From approximately 8 weeks post partum the control ewes began to gain weight, whereas the Co-depleted ewes did not and those which had given birth to twins (ewes A4 and A5) began to lose weight faster than did the ewes which gave birth to single lambs. The pair of twin lambs born to ewe A4 were killed when they were 10 weeks old, each having gained only $2.5 \mathrm{~kg}$ in weight since birth; their serum vitamin $B_{12}$ values were 190 and $25 \mathrm{pg} / \mathrm{ml}$ and that of their dam was $70 \mathrm{pg} / \mathrm{ml}$. The twin lambs born to ewe A5 were equally unthrifty at 10 weeks of age and one was killed (serum vitamin $B_{12} 60 \mathrm{pg} / \mathrm{ml}$ ), whilst the other was given $\mathrm{CoSO}_{4}$ in its drinking water $(70 \mu \mathrm{g} \mathrm{Co} / 1)$, resulting in a rapid improvement in its condition and a concomitant increase in its serum vitamin $B_{12}$ content from 70 to $1060 \mathrm{pg} / \mathrm{ml}$ within 2 weeks. The single lamb born to ewe A2 did not appear unthrifty until, at 16 weeks of age, its condition rapidly deteriorated and it was killed (serum vitamin $B_{12} 90 \mathrm{pg} / \mathrm{ml}$ ). The remaining lamb (born to ewe Al), after gaining weight for 6 months, began to lose weight gradually and it was killed (aged 32 weeks) when its serum vitamin $B_{12}$ value was $235 \mathrm{pg} / \mathrm{ml}$.

\section{Group $B$ ewes and their lambs}

The five experimental ewes in this group had already eaten the Co-deficient diet for 16 weeks when they were re-mated and were thus considerably depleted of vitamin $B_{12}$ before pregnancy began, as the serum values given in Table 3 indicate. From the time of re-mating their appetites declined steadily and, though they all lost weight, parturition took place at normal term as it did in group $A$.

The vitamin $B_{12}$ content of the sera of the ewes and their urinary output of MMA at 12, 9 and 3 weeks pre partum are shown in Table 4. Throughout pregnancy the vitamin $B_{12}$ values were generally similar to those at the time of re-mating, though two particuarly low values ( 35 and $95 \mathrm{pg} / \mathrm{ml} \mathrm{serum)}$ were recorded 3 weeks before term for ewes B4 and B5 respectively. With the exception of one animal (ewe B3), the urinary excretion of MMA at 12 and 9 weeks pre partum was not abnormally high; however, 3 weeks before term, enhanced output of MMA was occurring, by which time ewe B3 was excreting a considerable amount of the acid. 
Table 3. Serum vitamin $B_{12}$ values of ewes in group $B$ at time of mating (after consuming the cobalt-deficient diet for 16 weeks)

\begin{tabular}{ccc}
\hline \hline & $\begin{array}{c}\text { Serum vitamin } \\
\text { Ewe no. }\end{array}$ & $\mathbf{B}_{\mathbf{1 2}}(\mathrm{pg} / \mathrm{ml})$ \\
\hline & B1 & 190 \\
B2 & 275 \\
B3 & 305 \\
B4 & 215 \\
B5 & 145 \\
\hline
\end{tabular}

Table 4. Effect of cobalt deficiency in pregnant ewes (group $B$ ) on serum vitamin $B_{12}$ values and urinary output of methylmalonic acid (MMA)

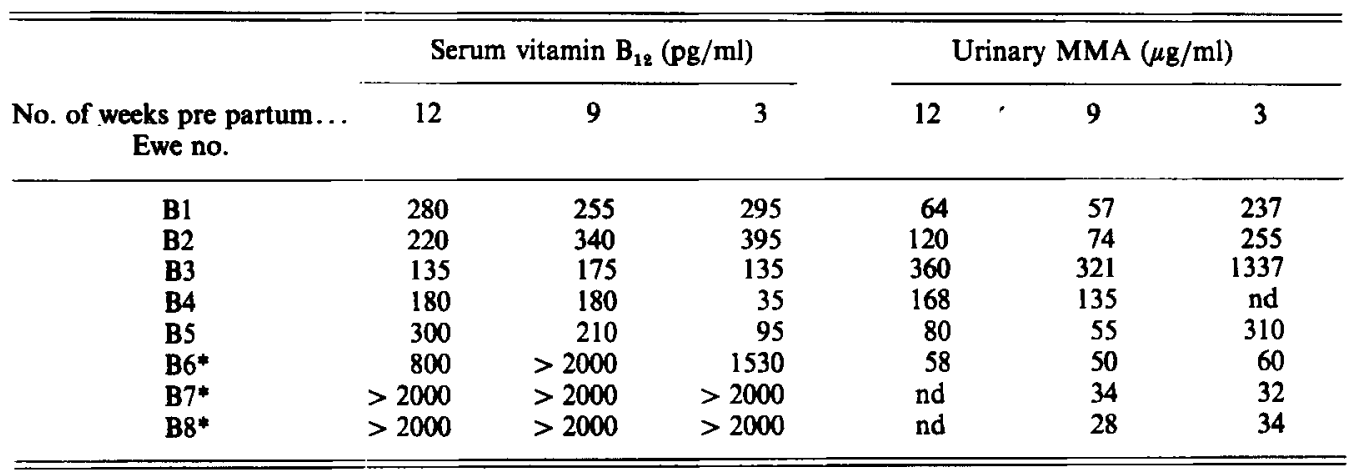

nd, not determined.

* Control animal given supplementary cobalt.

Table 5. Proportions of odd-numbered fatty acids (ONFA) and branched-chain fatty acids $(B C F A)$ in liver and adipose tissue lipids of lambs born to vitamin $B_{12}$-depleted ewes

(Values as percentage by weight of total fatty acids in each class of lipid)

\begin{tabular}{|c|c|c|c|c|c|c|}
\hline \multirow{3}{*}{$\begin{array}{l}\text { Lamb born } \\
\text { to ewe no. }\end{array}$} & \multicolumn{4}{|c|}{ Liver } & \multirow{2}{*}{\multicolumn{2}{|c|}{$\begin{array}{l}\text { Adipose tissue } \\
\text { triacylglycerols }\end{array}$}} \\
\hline & \multicolumn{2}{|c|}{ Neutral lipids } & \multicolumn{2}{|c|}{ Phospholipids } & & \\
\hline & ONFA* & BCFA $†$ & ONFA* & BCFA $\dagger$ & ONFA* & BCFAt \\
\hline A7 & 4.7 & 0.4 & $5 \cdot 3$ & 1.0 & 4.4 & 0.2 \\
\hline A7 & 7.4 & 1.2 & $7 \cdot 3$ & 1.5 & $4 \cdot 6$ & 0.5 \\
\hline B2 & $5 \cdot 3$ & 1.5 & 3.4 & 0.8 & 10.0 & 1.9 \\
\hline B3 & $10 \cdot 7$ & 2.5 & 12.3 & 2.4 & 13.3 & 3.8 \\
\hline B4 & $10 \cdot 7$ & $1 \cdot 1$ & $14 \cdot 2$ & 1.5 & nd & nd \\
\hline B6t & 1.4 & 0.5 & 1.4 & 0.5 & 1.2 & 0.8 \\
\hline B $7 \ddagger$ & 1.7 & 0.4 & $2 \cdot 1$ & $1 \cdot 1$ & 0.4 & 0.1 \\
\hline B8‡ & 2.2 & 0.5 & 1.9 & 1.8 & 0.3 & $0 \cdot 1$ \\
\hline
\end{tabular}

nd not determined.

- Comprising 15:0, 17:0 and 19:0, together with 17:1 and 19:1.

$\dagger$ Mostly monomethyl substituted 14:0, 15:0, 16:0 and 17:0.

$\ddagger$ Control animal given supplementary cobalt. 
Perinatal mortality and morbidity was high among the lambs born to these vitamin $B_{12}$-depleted ewes. Ewe B3 produced stillborn twins and one of the twins born to ewe B5 was also stillborn; the other lamb.(very small) was apparently unable to be suckled and it was killed. Twins born to ewe B4 died at birth and the two lambs produced by ewe B1 were very weak and were not suckled by their dam; they were killed $1 \mathrm{~d}$ after birth, as was also the single lamb born to ewe B2 since it also did not appear to have been suckled. The control ewes (B6, B7 and B8) produced normal healthy lambs which were killed shortly after birth.

\section{Lipid analyses}

The percentages of ONFA and BCFA which were found in the tissue lipids of the lambs born to Co-depleted ewes are given in Table 5. With respect to liver lipids, the characteristic feature of both the neutral lipids and the phospholipids is their enhanced content of ONFA compared with that in the corresponding lipid fractions from the livers of control animals; particularly noteworthy are the values $(>10 \%)$ for the ONFA content of the hepatic fatty acids of the lambs produced by ewes B3 and B4. The amounts of ONFA present in the adipose tissue triacylglycerols paralleled those which occurred in the liver lipids. No such outstanding differences in the content of BCFA were found between the tissue lipids of vitamin $B_{12}$-deprived lambs and control lambs.

\section{DISCUSSION}

Effects of vitamin $B_{12}$ depletion on the ewes and the viability of their lambs

As Table 1 shows when the sera of the ewes in group A were first assayed ( 5 weeks pre partum) for their content of vitamin $B_{12}$, the values for the animals which received the Co-deficient diet were already low (ranging from 150 to $340 \mathrm{pg} / \mathrm{ml}$ ) and similar values were recorded for the remainder of pregnancy. Compared with that of the control ewes, the urinary content of MMA during late pregnancy was not apparently abnormal, except for ewe A7, the urine of which even 5 weeks before term contained $>200 \mu \mathrm{g} \mathrm{MMA} / \mathrm{ml}$ and this increased to nearly $300 \mu \mathrm{g} / \mathrm{ml} 1$ week before parturition. It is perhaps noteworthy (see previous section) that this ewe was the only one in group $A$ the lambs of which died at birth; all the other lambs produced by the Co-depleted ewes in this group appeared normal at birth in their general appearance and behaviour. However, most of these lambs failed to thrive and all but three succumbed to vitamin $B_{12}$ depletion (serum $B_{12}<100 \mathrm{pg} / \mathrm{ml}$ ) before the normal weaning time of 12 weeks.

From the foregoing observations it is evident that, although ewes can consume a Co-deficient diet throughout pregnancy and their vitamin $\mathbf{B}_{12}$ status can be markedly affected, no overt signs of this condition may manifest themselves until the ewes begin to lose their appetites, and their lambs fail to thrive and succumb to vitamin $B_{12}$ deprivation from about 2 months post partum.

If, however, the period of vitamin $B_{12}$ insufficiency extends for some time before pregnancy, as it did in the instance of group B ewes, then signs of low vitamin $B_{12}$ status (unthriftness and loss of appetite) become evident during pregnancy and perinatal mortality among the lambs is high. Associated with the prolonged period of vitamin $\mathbf{B}_{12}$ deprivation and the loss of appetite of the ewes was a considerably enhanced output of urinary MMA (see Table 4), indicating that catabolism of tissue proteins may well have been occurring in these animals. Whether or not high plasma concentrations of MMA in the pregnant ewe are directly associated with failure to produce viable lambs remains to be investigated. 
Fatty acids of lamb tissues

Previous studies in this laboratory (Garton et al. 1972; Duncan et al. 1974) showed that, when sheep are fed on ciets rich in readily fermentable carbohydrate, their depot lipids contain unusually high percentages of ONFA and BCFA. Propionate arising from rumen fermentation is available in enhanced amounts to such animals and it evidently becomes available as a 'primer' unit for the biosynthesis of ONFA. Hepatic metabolism of propionate normally inviolves its carboxylation to MMA which, in turn, is converted to succinate by a vitamin $\mathbf{B}_{12}$-dependent enzyme system (methylmalonyl-CoA mutase). If this enzyme system is 'overloaded' or if the amount of active enzyme is reduced (cf. Elliot, 1980), MMA can become available to replace malonate as a chain-extension unit during fatty acid synthesis, thereby giving rise to BCFA containing one or more methyl branches in the acyl chain (Scaife et al. 1978; Smith et al. 1979). Since the mutase is dependent on vitamin $B_{12}$ for its activity, animals depleted of the vitamin might thereby be expected to synthesize more ONFA and BCFA than they otherwise would do. Thus, in vitamin $\mathbf{B}_{12}$-deficient baboons, Garton $e$ al. (1975) found somewhat enhanced proportions of both ONFA (mostly 15:0 and 17:0) and BCFA in liver lipids and, in vitamin $B_{12}$-depleted rats, Fehling et al. (1978) reported that the lipids of several tissues (including liver, adipose tissue and brain) contained more ONFA (15:0 and 17:0) than did the corresponding lipids from control animals. It was therefore not altogether suprising to find, as Table 5 shows, that the neutral lipids and phospholipids of the live: and the triacylglycerols of the adipose tissue of lambs born to vitamin $\mathbf{B}_{12}$-depleted ewes contained notably greater proportions of ONFA than were found in the tissues of control larnbs, the composition of which was similar to that previously found in this laboratory for nornal neonatal lambs (Garton \& Duncan, 1969). No such clear-cut difference between vitamin $B_{12}$-depleted lambs and controls is evident so far as the BCFA content of liver lipids and adipose tissue triacylglycerols is concerned, though it is of interest to note that lipids from the tissues of lamb B3, which contained a particularly high percentage of ONFA, alsc had the highest percentage of BFCA. Thus, despite the likelihood that maternal MMA is available to the lamb in utero, it is apparently not as extensively utilized for fatty acid synthesis as is propionate.

Whether or not ONFA, and possibly BCFA, accumulate in other tissues such as brain and spinal cord will be investigated in future experiments, particuarly in the light of preliminary observations (B. F. Fell, unpublished) that lesions are present in the nervous tissue of some of the vitamin $B_{12}$-deprived lambs of our present study.

The authors wish to thank Miss G. McIntosh for her skilled assistance and Mr T. Atkinson for the vitamiา $\mathrm{B}_{12}$ assays. Thanks are also accorded to $\mathrm{Mr} \mathrm{J}$. C. Burridge (Macaulay Institute, Aberdeen) for the cobalt analyses. E. R.M. took part in this work as the holder of a post-graduate Studentship awarded by the Wellcome Trust.

\section{REFEREN CES}

Andrews, E. D. (1956). N.Z. Jl Agric. 92, 239.

Andrews, E. D. \& Stephenson, B. J. (1966). N.Z. Jl agric. Res. 9, 491.

Christie, W. W. (1973). Lipid Analysis, 1st ed. Oxford: Pergamon Press.

Duncan, W. R. H., Lough, A. K., Garton, G. A. \& Brooks, P. (1974). Lipids 9, 669.

Elliot, J. M. (1980). In Digestive Physiology and Metabolism in Ruminants, p. 485 [Y. Ruckebusch \& P. Thivend, editors]. Lancaster: MTP Press.

Fehling, C., Jägerstad, M., Åkesson, B., Axelsson, J. \& Brown, A. (1978). Br. J. Nutr. 39, 501.

Feliński, L., Garton, G. A., Lo Igh, A. K. \& Phillipson, A. T. (1964). Biochem, J. 90, 154.

Garton, G. A. \& Duncan, W. F.. H. (1969). J. Sci. Fd Agric. $20,39$.

Garton, G. A., Hovell, F. D. DeB. \& Duncan, W. R. H. (1972). Br. J. Nutr. 28, 409.

Garton, G. A., Scaife, J. R., Smith, A. \& Siddons, R. C. (1975). Lipids 10, 855. 
344 W. R. H. Duncan, E. Rona Morrison and G. A. Garton

Gawthorne, J. M. (1968). Aust. J. biol. Sci. 21, 789.

Giorgio, A. J. \& Plaut, G. W. E. (1965). J. Lab. clin. Med. 66, 667.

Scaife, J. R., Wahle, K. W. J. \& Garton, G. A. (1978). Biochem. J. 176, 799.

Smith, A., Calder, A. G., Lough, A. K. \& Duncan, W. R. H. (1979). Lipids 14, 953.

Underwood, E. J. (1977). Trace Elements in Human and Animal Nutrition. 4th ed., p. 132. London: Academic Press. 